\title{
Algunos nuevos paradigmas sobre la Libertad de Expresión
}

\author{
Editado por/Edited by: Gabriela Albuja / Alejandro Briones \\ Recibido/Received: 9/11/2014. Aceptado/Accepted: 16/05/2015 \\ Publicado en línea/Published on Web: 16/10/2015
}

\author{
Víctor Cabezas \\ Universidad San Francisco de Quito, Colegio de Jurisprudencia JUR \\ Diego de Robles y Vía Interoceánica, Quito, Ecuador \\ Correo Electrónico:vdcabezas@gmail.com
}

\section{Resumen}

En los últimos años, se han acentuado las críticas al ejercicio de la libertad de expresión. Esto ha ocurrido especialmente en Latinoamérica con el surgimiento de los denominados regímenes políticos del socialismo del siglo XXI. En este artículo se trata la ambivalencia entre la importancia de la libertad de expresión como derecho humano -reconocido en los distintos instrumentos internacionales- y la prevalencia de grandes grupos económicos concentradores de medios de comunicación. A la luz de este análisis, se abordarán los retos de la libertad de expresión, en particular el concepto de censura previa estructural.

Palabras clave: Libertad de expresión, concentración de medios, derecho humano, censura previa, censura estructural.

\section{Abstract}

The exercise of freedom of expression has been subject to criticisim during the latest years in latinamerica. These critics have been promoted by the so called 21 st century socialist governments of the region and is mainly founded on the predominance of private economic interests inside the legitimate defense of a human right. In this sense, an ambibalence between the importance of freedom of expression and the finnancial interests of large mass media enterprises will be analyzed in the present paper. Moreover, we will adress the new challenges of this human right facing new structures of censorship that, currently, does not necessarily comes from the State.

Keywords: Freedom of expression, media concentration, human right, prior censorship, structural censorship.

\section{Introducción}

$\mathrm{E}$ 1 debate sobre el contenido de la libertad de expresión como derecho humano ha escalado las esferas jurídicas y se ha insertado de lleno dentro del debate político en las sociedades latinoamericanas. Éste ha sido categorizado como fundamental y constituye una piedra angular en las sociedades democráticas (CEDH, 1976, p. 24).

En América Latina, la concentración de medios de comunicación ha sido un fenómeno mercantil histórico que nos ha legado verdaderos oligopolios mediáticos. Una falsa sensación de pluralismo e independencia se ha consolidado en los discursos de legitimación de las radios, periódicos y televisoras. En medio de este agreste panorama los ciudadanos debemos encontrar espacios para discernir el bagaje de información y opinión que presentan los medios y a su vez desenterrar espacios para expresar nuestra propia opinión.

Partiendo del entendido de que la libertad de expresión constituye una manifestación inherente a la condición humana y su vigencia es fundamental para la sustanciación del catálogo de derechos humanos, cabe preguntarnos: ¿Hasta qué punto la concentración de medios por parte de grandes corporaciones 
construye y fomenta la plena vigencia de esta libertad civil? ¿Hasta qué punto la comercialización de la información se vuelve una contradicción de facto para el ejercicio pleno por parte del ciudadano?

La respuesta a estas preguntas constituirá el eje rector del presente artículo. Abordaremos la línea argumentativa partiendo desde la introducción a la libertad de expresión como derecho humano y realizaremos un estudio de caso focalizado en Estados Unidos y México. Finalmente referiremos el estándar internacional de derechos humanos en relación a la censura previa y cómo, frente a la nueva relación de medios de comunicación, este concepto ha transfigurado.

\section{Acercamiento al concepto de libertad de ex- presión}

La libertad de expresión es un derecho humano contenido en la mayoría de instrumentos internacionales tales como la Declaración Universal de los Derechos Humanos (DUDH) o la Convención Americana sobre Derechos Humanos (CADH). El artículo 19 de la DUDH menciona lo siguiente ${ }^{1}$ :

Todo individuo tiene derecho a la libertad de opinión y expresión; este derecho incluye el de no ser molestado a causa de sus opiniones, el de investigar y de recibir informaciones y opiniones, y el de difundirlas, sin limitación de fronteras, por cualquier medio de expresión.

Es menester dar lectura al estándar interamericano, en materia de derechos humanos, que prescribe la definición, alcances y limitaciones del derecho a la libertad de expresión. Así, el artículo 13 de la CADH menciona:

1. Toda persona tiene derecho a la libertad de pensamiento y de expresión. Este derecho comprende la libertad de buscar, recibir y difundir informaciones e ideas de toda índole, sin consideraciones de fronteras, ya sea oralmente, por escrito o en forma impresa o artística, o por cualquier otro procedimiento de su elección y gusto.

1 La libertad de expresión también se encuentra reconocida en la Declaración Americana sobre los Derechos y Deberes del Hombre, Pacto Internacional de Derechos Civiles y Políticos, Convención Europea sobre Derechos Humanos, entre otros instrumentos de protección.
2. El ejercicio del derecho (...) no puede estar sujeto a previa censura sino a responsabilidades ulteriores, las que deben estar expresamente fijadas por la ley y ser necesarias para asegurar:

a) El respeto a los derechos o la reputación de los demás.

b) La protección de la seguridad nacional, el orden público o la salud o la moral públicas.

3. No se puede restringir el derecho de expresión por vías o medios indirectos, tales como el abuso de controles oficiales o particulares de papel para periódicos, de frecuencias radioeléctricas o de enseres y aparatos usados en la difusión de información o por otros medios encaminados a impedir la comunicación y la circulación de ideas y opiniones (CrIDH, 2004, p. 107).

4. Los espectáculos públicos pueden ser sometidos por la ley a censura previa con el exclusivo objeto de regular el acceso a ellos para la protección moral de la infancia y la adolescencia, sin perjuicio de lo establecido en el inciso.

5. Estará prohibida por la ley toda propaganda en favor de la guerra y toda apología del odio nacional, racial o religioso que constituyan incitaciones a la violencia o cualquier otra acción ilegal similar contra cualquier persona o grupo de personas, por ningún motivo, inclusive los de raza, color, religión u origen nacional.

Tanto a nivel doctrinario como a nivel de casos contenciosos llevados ante organismos internacionales supervisores de derechos humanos, existen dos dimensiones del derecho a la libre expresión. Por un lado, hallamos la dimensión individual, sea la posibilidad que tienen los ciudadanos de emitir comentarios, participar en el flujo de información, opinar y generar debate (CrIDH, 2004, p. 107). Por otro lado, existe la dimensión colectiva que se refiere al derecho de la sociedad a buscar, recibir, analizar y difundir información.

Una vez denotadas las dos dimensiones del derecho humano a la libertad de expresión, es importante detallar que su violación no se limita a la esfera individual sino que trasciende a una violación al derecho que todos tenemos a recibir aquella información que el otro poseía y que no pudo ser difun- 
dida (Sagues, 1997, p. 21). Tal como lo ha denotado la Corte Interamericana de Derechos Humanos en su Opinión Consultiva OC-5/85:

En su dimensión individual, la libertad de expresión no se agota en el reconocimiento teórico del derecho a hablar o escribir, sino que comprende además, inseparablemente, el derecho a utilizar cualquier medio apropiado para difundir el pensamiento y hacerlo llegar al mayor número de destinatarios. Por otro lado, En su dimensión social la libertad de expresión es un medio para el intercambio de ideas e informaciones y para la comunicación masiva entre los seres humanos. Así como comprende el derecho de cada uno a tratar de comunicar a los otros sus propios puntos de vista implica también el derecho de todos a conocer opiniones y noticias. Para el ciudadano común tiene tanta importancia el conocimiento de la opinión ajena o de la información de que disponen otros como el derecho a difundir la propia. Estas dimensiones deben ser garantizadas simultáneamente. (...)en principio la libertad de expresión requiere que los medios de comunicación social estén virtualmente abiertos a todos sin discriminación (CrIDH, 1985, 32).

Las dos dimensiones son interdependientes en el sentido en que sería imposible mentalizar un panorama donde el ciudadano pueda ejercer plenamente su derecho a la libertad de expresión activo -es decir escribiendo, hablando o expresándose en general- sin poder ser sujeto pasivo de aquel derecho -informándose a través de medios de comunicación, etc.- En nuestra opinión, la vigencia de la libertad de expresión como derecho humano está directamente determinado por la convivencia armónica y garantizada de su espectro pasivo y activo.

En un escenario en el cual exista una marcada concentración de medios de comunicación en un cúmulo de empresas o familias: ¿Estaríamos observando una flagrante violación a la libertad de expresión en su dimensión pasiva/colectiva? Evidentemente una consecuencia directa de la concentración de medios será la polarización de la información, del flujo ideológico, de las fuentes de información y finalmente de la opinión pública (Lopez-Galliacho, 2010, p. 202). Esto genera limitaciones de acceso tanto a una información veraz como a una participación ciudadana dentro de la dinámica comunicacional de una sociedad. La puesta en circulación de mensajes, prerrogativas de debates y marcos de la agenda de opinión pública por parte de los grandes medios de comunicación constituye una limitación directa a la libertad de expresión de los individuos. Recordemos que de acuerdo al artículo 13 de la CADH, la concentración de la propiedad de medios de comunicación es una limitación indirecta de la libertad de expresión.

Queda muy claro cómo la concentración de medios de comunicación en pocas empresas es directamente incompatible con el ejercicio pleno del derecho humano a la libertad de expresión. Esto en razón de que la polarización de la opinión pública y la definición de las líneas editoriales, de lo que es noticioso o no, emitido desde las altas esferas de poder de las empresas controladoras de medios de comunicación, limitan la dimensión pasiva del derecho humano a la libertad de expresión.

Terminaremos esta breve introducción al concepto de libertad de expresión ratificando la importancia que su defensa representa, especialmente en relación con la posibilidad de dar plena vigencia a los otros derechos humanos. Sería muy complejo facultar la defensa del derecho humano a la vida, a la integridad personal o a la vida digna, sin hacer pleno uso del derecho humano a la libertad de expresión. En este sentido, esta libertad civil posee un carácter instrumental.

\section{Efectos de la concentración de medios de co- municación}

Los medios de comunicación son entidades que cumplen un rol fundamental para la vigencia del derecho a la libre expresión. Por tanto, en la medida en que son libres e independiente, garantizan los derechos de las personas (Shawn, 2003, p. 178). La falta de independencia y libertad en los medios generan en cierta medida estados de censura previa que atentan directamemente contra la esencia del derecho.

Los grandes líderes de las empresas de comunicación son constructores de política pública. Sin embargo, cabría plantear qué tanta legitimidad puede tener un actor privado para determinar aquello relevante para la opinión pública y más aún ¿cómo podemos compaginar el legítimo derecho de un privado a 
lucrar con el de la sociedad a ser informado?

El dueño de un periódico o de un medio masivo de comunicación es un comerciante y los proyectos editoriales-mediáticos bien pueden ser comprendidos como grandes proyectos mercantiles. Podríamos sostener que existe una contradicción de base entre el deber de informar y la exigencia mercantil de lucrar.

La función del Estado en este aspecto es velar por el pluralismo y la diversidad de los medios de comunicación. Esto se puede lograr a través de la creación de leyes antimonopólicas en la propiedad de los medios de comunicación, además de la regulación de la distribución equitativa de su propiedad. Por ejemplo, se ha planteado en Francia que los periodistas deben tener una cuota en las acciones de la empresa donde laboran para que el control de calidad sea su único fin. Sin embargo la ampliación de este tipo de medidas se ha obnubilado en razón de que un cambio siempre significará una pérdida de poder por parte del tenedor del capital (Shawn, 2003, p. 372).

Hoy en día las percepciones sociales se encuentran totalmente vinculadas con lo que sucede en las salas de redacción. La información en su estado puro es moldeada por una serie de criterios que van desde el libre albedrio del editor en jefe, los compromisos económicos de los medios e inclusive el target de público al que se dirige (Ansuátegui, 1992, p. 34). La opinión pública está limitada por el espectro de información que la prensa erige. Los grandes ideales también se construyen desde las salas de redacción y desde la política editorial de los medios de comunicación.

Es extremadamente necesario para la sociedad promulgar un debate, entre esferas académicas, Estado, gremios profesionales y sociedad civil conducente hacia el re pensamiento de las relaciones de poder. Esto a efectos de precautelar la plena vigencia de la libertad de expresión por parte de periodistas y ciudadanos en general (Boykoff, 2004, p. 1190).

\section{Presentación de estudios de caso concreto}

\subsection{Estados Unidos: la verdad a nom-} bre de seis grandes corporaciones.

El caso de Estados Unidos es extremadamente preocupante en términos de acceso a la libertad de expresión. En 1983, 90\% de los medios de comunicación eran manejados por 50 empresas (Chomsky, 2002 , p. 157). Esto fue considerado -en su momentocomo una nueva dictadura de medios de comunicación (Chomsky, 2002, p. 201). Gracias a la falta de diligencia estatal a la hora de controlar el crecimiento concentrador de las corporaciones mediáticas, en 2011 hubo una regresión abrupta en la distribución de los medios. Últimas cifras extraoficiales advierten que 6 empresas controlan el 90\% (Media Consollidation Agency, 2015, p.2) de los periódicos, canales, radios y portales web noticiosos (Boykoff, 2004, p. 1204):

\section{NBCUniversal Inc:}

Sus actividades se centran en la producción y mercadeo de noticias, entretenimiento, servicios informativos, publicidad, etc. Entre los medios concentrados por NBCUniversal se encuentran: NBC, Universal Studios, NBC News, USA Network, CNBC, Syfy, MSNBC, iVillage, Telemundo, The Weather Channel, Hulu, entre otras.

\section{News Corporation}

Es una empresa multinacional estadounidense dedicada a la operación de medios de comunicación. Para 2008, generó ingresos por más de 29 millones de dólares. Además concentra 152 medios de comunicación regionales, nacionales e internacionales. Dentro de sus marcas más conocidas y de mayor alcance encontramos a: Wall Street Journal, New York Post, The Sun, The Australian.

\section{Viacom Inc}

Es un conglomerado de medios de comunicación destinado a la producción de entretenimiento multisectorial, noticias y desarrollo de nuevos medios (Waterman, 1999, p. 531). A partir de 2010 es el cuarto más grande del mundo después de Walt Disney, Time Warner y News Corporation. Dentro de sus marcas más conocidas hallamos a MTV, Nickelodeon, Paramount Pictures, Dream Works, etc.

\section{Time Warner}

El segundo mayor conglomerado de medios de comunicación del mundo tiene ingresos por más de 28 mil millones de dólares y se calcula que con- 
trola 1 de cada 3 noticias que sale dentro del espectro mediático en Estados Unidos. Entre sus principales marcas encontramos a: CNN (primer canal de noticias del mundo), Chilevisión, CNN en español, HBO, TNT, Cartoon Network, Warner Channel, Radio Caracas Televisión, Revistas Time, Revista People, Grupo Expansión, DC Comics, Warner Bros, entre muchos otros más (Faulhaber, 2002, p. 311).

Este panorama es, por decir lo menos, preocupante. Sin perjuicio de la gran concentración de medios existente $-\mathrm{y}$ su estado de incongruencia fáctica con los estándares de libertad de expresión-, existe un discurso social conducente hacia la glorificación de la situación de los derechos civiles en ese país.

En Estados Unidos se ha erigido un verdadero imperio de los medios de comunicación que han ofuscado la participación de los ciudadanos dentro de las pantallas, las revistas y los periódicos. La opinión pública que leen más de 300 millones de americanos se dibuja desde los escritorios de 232 ejecutivos, cuyas columnas, titulares y programas de entretenimiento relegan más de 275.9 billones de dólares en utilidades.

\subsection{México: cuando una televisora es un poder político todopoderoso.}

Si bien la libertad de expresión en México ha sido un fenómeno ampliamente abordado desde la situación vulnerable bajo la cual los periodistas se ven forzados a ejercer su profesión, la problemática concentración de medios en este país ha sido carente de estudio. El panorama es tan simple como consternarte. Dos empresas - Televisa y Televisora Aztecacontrolan la totalidad del flujo informativo del país de más de 100 millones de habitantes.

El célebre sociólogo mexicano Trejo Delabre ha manifestado que "Cuando pocas empresas tienen un mercado de ese tamaño- Televisa, TV Azteca y Telmex adquieren un poder gigantesco y se convierten en actores políticos" (Trejo, 2012, p. 12). El hecho de tener dentro de una sociedad a un pequeño conglomerado de poderosos medios de comunicación genera una ilegítima opresión contra los poderes soberanos -aquellos democráticamente electos-. Las grandes empresas de medios, acostumbran a direccionar la opinión pública y por ende a parcializar la tendencia electoral.
Televisa ha sido uno de los grandes actores electorales de la historia mexicana. Coadyuvó en la perenización del Partido Renovador Institucional por más de 70 años en el poder -dentro de la llamada "dictadura perfecta" (Paxmann, 2011, p. 64) Dentro de los últimos comicios electorales del 2012, el diario inglés "The Guardian" publicó una serie de documentos que vinculaban el financiamiento de la campaña del candidato del PRI Enrique Peña Nieto a la Televisora mexicana (The Guardian, 2012, p. 2). Anteriormente ya se habían develado un conjunto de documentos del año 2005 que detallan la venta de cobertura favorable - por parte de Televisa- a ciertos políticos entre los que estaba incluido Peña Nieto. Los documentos también parecían contener evidencia de una campaña de desprestigio orquestada desde la empresa en contra de Andrés Manuel López Obrador que en esos momentos estaba preparando su primera campaña presidencial.

El panorama de polarización extrema que vive México se materializa con el poderío mediático que concentra Televisa; su negocio ha acaparado todos los espectros de difusión masiva de información:

a) Televisa Radio es propietaria de las 5 marcas de radio que operan en todo el país;

b) Editorial Televisa es la editorial de revistas en español más grande del mundo. Actualmente controla más del $65 \%$ de las publicaciones que fluyen en América Latina. Dentro de sus revistas más icónicas hallamos a PC Magazine en español, Cosmopólitan, Mecánica Popular, Buenhogar, TV y Novelas, Teleguía, Eres, Cine Premier, Quo y Saber Ver, entre otras. Editorial Televisa posee alrededor de 172 títulos bajo 107 marcas. Se estima que vende alrededor de 165 millones de revistas en más de 20 países.

A riesgo de recaer en un discurso pesimista, el panorama en México está muy lejos de mejorar. Las dos mayores televisoras abiertas del país acaparan casi el $100 \%$ de los 42,000 millones de pesos mexicanos que genera este mercado, y el Instituto Federal de Telecomunicaciones (IFT) proyecta que en cinco años los nuevos participantes deben arrancar al menos 8.5\% (Sigler, 2012, p. 2) del mercado consolidado por las televisoras para poder ser competidores reales, algo que jamás sucederá. 


\section{Libertad de expresión y censura previa, ante un nuevo paradigma.}

En la actualidad, cabría preguntarse cual es la relación de poderes en la sociedad. Si bien podríamos partir desde la concepción divisoria tradicional de poder ejecutivo, judicial y legislativo, propuesto por Montesquieu, la coyuntura actual de poder es cada vez más alejada de esta tensión tripartita desarrollada en la ilustración. La globalización, la expansión de los mercados, entre otras cosas, han generado una convergencia de nuevos actores en el poder.

Así las cosas, podríamos identificar como el primer gran poder al económico, y como segundo, ciertamente, al mediático. De forma que el poder político queda relegado a un tercer plano (Ramonet, 1998, p. 32). Los televisores de Naciones Unidas están constantemente transmitiendo grandes cadenas de noticias norteamericanas y la agenda de sesiones en sus distintos organismos se dibuja, en gran medida, a partir de aquello que es mediáticamente relevante. En efecto, el poder político ha pasado a un plano meramente ejecutivo y directriz de aquellas prioridades que los medios de comunicación establecen (Ramonet, 1998, p.38)

Si bien es muy importante analizar como este cambio dentro de las relaciones de poder en sociedad afectan la política y a su vez los derechos civiles es menester preguntarnos ¿cómo funciona la comunicación? ¿a qué estructuras responde? ¿a qué intereses protege? Dentro del análisis general del rol contemporáneo de los medios de comunicación la censura previa (Ramonet, 1998, p. 40).

Acontinuación analizaremos la transfiguración que la manifestación de la censura previa ha sufrido, junto con los nuevos paradigmas que plantea la libertad de expresión. El artículo 13.2 de la $\mathrm{CADH}$ contiene una clara e intencional distinción entre «censura previa»y «responsabilidades ulteriores». La primera se encuentra prohibida a la luz de los estándares internacionales de derechos humanos, mientras que la responsabilidad ulterior es admitida, bajo circunstancias previstas en ley. El objeto de esta disposición es promover la publicación de contenido, inclusive aquel que moleste al poder o a las grandes mayorías, con la única sujeción a que aquel contenido pueda ser susceptible de responsabilidad una vez publicado. La Corte Interamericana, en la ya citada
Opinión Consultiva OC-5/85 ha dicho, que:

«...cuando se restringe ilegalmente la libertad de expresión de un individuo (censura previa), no sólo es el derecho de ese individuo el que está siendo violado, sino también el derecho de todos a «recibir» informaciones e ideas; ... Se ponen así de manifiesto las dos dimensiones de la libertad de expresión. En efecto, ésta requiere, por un lado, que nadie sea arbitrariamente menoscabado o impedido de manifestar su propio pensamiento y representa, por tanto, un derecho de cada individuo; pero implica también, por otro lado, un derecho colectivo a recibir cualquier información y a conocer la expresión del pensamiento ajeno

De igual manera, la Corte Interamericana de Derechos Humanos ha estipulado que cuando hay censura previa se produce «una supresión radical de la libertad de expresión» al impedirse «la libre circulación de informaciones, ideas, opiniones o noticias. Esto constituye una: violación radical tanto del derecho de cada persona a expresarse como del derecho de todos a estar bien informados, de modo que se afecta una de las condiciones básicas de una sociedad democrática (CrIDH, 1985, p. 54).

La censura consiste principalmente en suprimir, amputar o prohibir un número determinado de hechos, aspectos o mecanismos idóneos para que el informado se acerque a la información. La confluencia de nuevos medios de comunicación masivos han establecido nuevos paradigmas para el análisis de la eficiencia de las medidas de censura por parte de las estructuras de poder, sean estatales, sean privadas. En las democracias actuales, con un fuerte discurso de prevalencia -hasta cierto punto ciega e inocua- de las libertades civiles, entre ellas la libertad de expresión, el periodista puede ejercer, en el más amplio sentido de la palabra, su libertad para reportar e informar.

Pero estamos muy lejos de alcanzar un estatus de ausencia total de censura - cosa que podría llegar a ser utópica. Hoy, las modalidades de ejercer presión y censura sobre periodistas e informantes ha transfigurado. La censura opera gracias al 
inconmensurable flujo de información que tenemos a nuestra disposición. La amplísima oferta informativa limita tácitamente nuestro potencial para discernir su nivel de relevancia y de veracidad. Este punto es ejemplificado por el periodista y catedrático Ignacio Ramonet de esta manera:

Tomemos la Guerra del Golfo por ejemplo. Hoy ya sabemos que constituyó una gran manipulación, una fantástica operación de censura y un discurso, en consecuencia, de propaganda. Ésta no se relaciono mediante el principio autoritario de la prohibición, la supresión o la no cobertura . No se dijo: "Va a haber una guerra y no os la vamos a enseñar" Al contrario, se dijo "La vais a ver en directo". Y se dio tal cantidad de imágenes, que todo el mundo creyó que veía la guerra. Y después se dio cuenta que no la veía, que las imágenes eran señuelos, o que se habían grabado antes. Y de hecho, la guerra desaparecía hasta el punto de que Baudrillard pudo escribir un libro: La Guerra del Golfo no se ha producido. (Ramonet, 1998, p. 34)

Los paradigmas de la censura en la actualidad podrían, fácilmente, asemejarse a un vil engaño social. Mientras en las más férreas dictaduras el flujo de información es denegado abiertamente y la censura es manifiesta, en las democracias occidentales de corte liberal, se perpetua una, cada vez mayor, censura estructural en los medios de comunicación.

Desarrollemos el concepto censura estructural; cuando pensamos en censura previa, seguramente viene a nuestra mente un cúmulo de acciones por parte del Estado o de agentes privados conducentes hacia la restricción para el normal flujo de la información. Generalmente observamos el fenómeno de la censura dentro de un espectro visible, comprensible y cuyos responsables son identificables. Analizaremos el caso de la censura estructural de forma análoga a los estudios de la manifestación de violencia.

Johan Galtung, uno de los más importantes sociólogos y profesor emérito de la Universidad de Oslo ha desarrollado una de las teorías más importantes para el entendimiento de las interacciones de violencia y su rol dentro de la sociedad. Dentro de sus investigaciones, consta el denominado "triángulo de la violencia", esta teoría presenta una dinámica a través de la cual se observa la presencia de más de un tipo de violencia dentro de conflictos sociales.

Según la teoría de Galtung, la violencia directa, en su forma tradicionalmente concebida -un golpe, un balazo o un insulto- es tan solo una de las aristas a través de las cuales la violencia se puede manifestar en la sociedad. En este sentido, la foto de la violencia se asemeja mucho a un iceberg donde lo que vemos es apenas parte del complejo organismo sobre el cual se manifiesta. Para explicar su teoría, Galtung dibuja un triángulo en cuyos vértices yacen las tres principales formas de violencia que el ha identificado, a través de sus investigaciones. En el primer vértice observamos a la violencia directa, la forma tradicional de observancia de agresión física o psíquica, el golpe o el insulto.

A través de las líneas del triángulo, Galtung trasciende hacia la violencia de tipo estructural, esta se centra en la configuración de un sistema invisible, abstracto e intangible, orquestado por el Gobierno y/o los grupos de poder con el objeto de negar y objetar la satisfacción de las necesidades de los grupos sociales. Pensemos en violencia estructural cuando el Estado está diseñado de tal forma que privilegia a cierto grupo social frente a otro, un Estado que fomenta la desigualdad social, un sistema de salud deficiente, instituciones democráticas discriminatorias, toda una estructura diseñada para invisibilizar las necesidades de los distintos grupos sociales son formas de violencia estructural. Aunque dentro de la violencia estructural no exista una manifestación física de agresión, esta violencia es la gran generadora de conflictos dentro de las sociedades, el inconformismo social, la falta de Gobernanza y un sistema diseñado para privilegiar intereses sectarios terminan por ser tan catastróficos como el balazo, el golpe o el insulto.

Finalmente, Galtung expone la última forma de manifestación de la violencia, la violencia cultural. Pensemos en el lenguaje. Cuan seguido -y sin necesariamente desearlo- usamos palabras que aluden a grupos sexuales minoritarios como insultos; recordemos la infancia en las jugueterías donde el sistema y la cultura iba tejiendo el abanico de posibilidades que el niño o la niña tenía para definir su identidad sexual; desde la llamada "viveza criolla"-y nuestra condición cultural de pensar que siempre hay 
una salida por la tangente- hasta las canciones más sucias y lascivas para la integridad y dignidad de la mujer, que no son fruto aislado de la calentura de un cantautor y la efervescencia de la adolescencia, sino el resultado de un proceso sistemático de violencia cultural de género. Todas estas son formas de violencia cultural, se encuentra inscrita en nuestra más intima forma de relacionarnos y se torna imposible de combatir porque eso significaría combatirnos a nosotros mismos.

Contrario a lo que se creería, en general la violencia directa es la más fácil de erradicar por el simple hecho de que los actores son visibles e identificables, sin embargo la violencia cultural $\mathrm{y}$ estructural son parte de un sistema intangible, invisible y -en cierta medida- intransgredible, ergo se tornan prácticamente imbatibles.

Ciertamente podemos aplicar estos estudios al análisis de la censura. La censura directa -lo que análogamente analizamos como violencia directa- puede ser fácilmente identificada, valorada y enmendada. Regresemos a la censura estructural; donde la identificación de los sucesos y actores que la producen es difusa. Ya no censuramos a través de una ley mordaza, ahora se censura a través de estrategias de propaganda, a través de presiones financieras o, simplemente, a partir de los intereses políticos-económicos de los dueños de los medios de comunicación.

Si bien, en las democracias de occidente la manifestación de una censura directa es, cada vez, menos plausible y aceptada socialmente, la perpetuación de la censura estructural se ha ido progresivamente implantando. En términos generales, las agendas comerciales de los grandes de medios de comunicación generan un conflicto de intereses que comprometen directamente su política editorial; este, como lo hemos explicado antes, es un problema éticoprofesional y siempre es susceptible de probarse en contra.

\section{Conclusiones}

La naturaleza de las libertades es permanecer en constante cambio. Es perfectamente normal y entendible que, ante los nuevos escenarios que plantea el mundo globalizado, los medios de comunicación adquieran otros roles y atributos. Sin embargo, aquella transfiguración debe ir acompañada de un férreo escepticismo social y una reflexión profunda frente a los debates socio culturales vigentes.

Nos hallamos ante un sistema en el que ha desparecido la visibilidad de la censura, en consecuencia la acción humana frente a las nuevas estructuras de censura debe ser proactiva, investigativa $\mathrm{y}$-como ya hemos mencionado- escéptica

La democracia griega, donde el ciudadano participa activamente dentro de los procesos políticos de su polis, debe ser ejercida desde el "activismo informativo". El ciudadano está llamado a contrastar fuentes, a discernir la validez de la información, a buscarla de primera mano. El ejercicio para informar debe ser un ritual de activa participación política, donde exista disposición a reservar tiempo y energías para la búsqueda de información. Esperar que actores privados -así como públicos- puedan atribuirse y ejercer aquel enorme gravamen de informar a la sociedad, es utópico, engañoso y disfuncional ante la coyuntura vista.

\section{Referencias}

Boykoff, J. (2007). Journalistic Norms. New York: Geoforum.

Chomsky, N (2002). La propaganda y la Opinión Pública. Barcelona: Crítica, pp. 157.

CEDH (Corte Europea de Derechos Humanos) (2004). Handyside v United Kingdom, A (24).

rIDH (Corte Interamericana de Derechos Humanos) (2004). Herrera Ulloa v Costa Rica (Preliminary Objections, Merits, Reparations and Costs), C, 107.

CrIDH (Corte Interamericana de Derechos Humanos) (1985). Opinión Consultiva OC -5/85. Párrafo $32-40$

CrIDH (Corte Interamericana de Derechos Humanos) (1985). Opinión Consultiva OC-5/85. Párrafo 54.

CrIDH (Corte Interamericana de Derechos Humanos) (2009). Tristán Donoso v Panama (Preliminary Exception, Merits, Reparations and Costs), C (193). 
Davenport, C. (1999). Human rights and the democratic proposition. Journal of Conflict Resolution, 43 (1), 92-116.

Goldenberg, G. (2001). Legislative Studies Quarterly. Detroit: University of Michigan Press.

Faulhaber, G (2002). Network effects and merger analysis: instant messaging and the $A O L-$ Time Warner case, 26(5), 311-333.

Lopez-Galliacho, J (2010). Oligopolio de Medios de Comunicación Españoles. Madrid: Universidad Rey Juan Cuarlos.

Paxman, A., \& Saragoza, A. M. (2001). Globalization and Latin media powers: the case of Mexico's Televisa. New York: Continental Order pp. 64-85.

Sigler, E. (2012). Los cuatro retos para competir contra Televisa y TV Azteca Recuperado desde http://www.cnnexpansion.com/negocios/2014/09/03/los-4-retos-para-competircontra-televisa-y-tv-azteca

Reinish, L. (2011). Media Consolidation, the illussion of choice. Recuperado desde http://www. freepress.net/blog/11/11/22/media-consolidation-illusion-choice

Ramonet, I (1998). La Tiranía de la Comunicación. Madrid: Temas de Debate.

Sagués, N. (1997). Elementos de derecho constitucional. Madrid: Astrea.

Salazar, P., \& Rivas, R. G. (2008). El derecho a la libertad de expresión frente al derecho a la no discriminación: tensiones relaciones e implicaciones, Madrid: Paidos.

Schramm (1998) Mass Communications. Urbana: University of Illinois Press.

The Guardian News Policy Squad (2012). Mexico media scandal: Televisa's alleged collusion with Peña Nieto Recuperado desde http://www. theguardian.com/world/interactive/2012/ jun/08/mexico-media-scandal-televisa-penieto-claims
Trejo, M. (2012). Bajo el imperio de la comunicación. México DF: Editorial UNAM Sociología.

Waterman, J. (1999). CBS-Viacom and the effects of media mergers: An economic perspective. Federal Communications Law Journal, 52(3), 531. 